\title{
A LÍNGUA DE SINAIS E O GUIA-INTÉRPRETE COMO MEDIADOR NA EDUCAÇÃO DA PESSOA COM SURDOCEGUEIRA
}

\author{
THE SIGN LANGUAGE AND THE INTERPRETER GUIDE AS A MEDIATOR \\ IN THE EDUCATION OF THE PERSON WITH DEAFBLINDNESS \\ LA LENGUA DE SEÑAS Y EL GUÍA-INTERPRETE COMO \\ INTERMEDIARIO EN LA EDUCACIÓN DE LA PERSONA CON \\ SORDOCEGUERA
}

\author{
Wolney Gomes Almeida * \\ Jeremias Barreto Souza **
}

\begin{abstract}
Resumo
Refletir sobre a pessoa com surdocegueira e, sobretudo, o atendimento direcionado ao surdocego no contexto socioeducacional, constitui uma necessidade acadêmica, seja quanto à produção de conhecimentos teóricos, como às intervenções práticas. Essa problemática configura os caminhos percorridos pelo presente artigo, a fim de investigar a importância da atuação do profissional Guia-intérprete no atendimento a pessoas com surdocegueira, a partir das práticas comunicativas com surdocegos e caracterizando os fatores e aspectos que interferem em sua atuação profissional enquanto mediadores para a socialização do surdocego. A partir das contribuições teóricas sócio-interacionistas, este trabalho pauta suas reflexões pela compreensão de que a relação do sujeito surdocego com o meio constitui fator essencial para o desenvolvimento desses indivíduos. A pesquisa de caráter bibliográfico permite a análise sobre a falta de informações e de conhecimentos específicos sobre a deficiência como um fator determinante para o surgimento de barreiras de ordem estrutural, programática, atitudinal, arquitetônica, que atingem tanto a qualidade dos serviços prestados ao surdocego, quanto a realidade social desse indivíduo, uma realidade excludente e de segregação.
\end{abstract}

Palavras-chave: Guia-intérprete, Inclusão educacional, Inclusão social, Mediação, Surdocegueira.

\section{Introdução}

A reflexão sobre a pessoa com deficiência na perspectiva da diferença e da diversidade, tem se tornado palco de discussões em diversos espaços, seja no âmbito educacional, ou nos diversos setores da sociedade que contemplem a acessibilidade, o

\footnotetext{
Doutor em Educação pela Universidade Federal da Bahia - UFBA. Professor da Universidade Estadual de Santa Cruz - UESC. E-mail: wolney_22@yahoo.com.br

** Pós-graduado em Direito e Práticas Jurídicas Cível, Trabalhista e Previdenciária pela Faculdade de Ilhéus. Advogado e Assessor de Imprensa do Sindicato do Magistério Municipal Público de Itabuna SIMPI - BA. E-mail: jerebarreto@ yahoo.com.br
} 
direito e o desenvolvimento social de todos os indivíduos, sejam eles com alguma deficiência ou não.

Nesse contexto, destaca-se a grande necessidade de ampliar o conhecimento e as discussões a respeito da pessoa com surdocegueira, partindo da própria problematização sobre o que é essa deficiência, como ela se constitui na formação do indivíduo inserido na sociedade, quais relações se dão para seu desenvolvimento e inserção nos espaços, considerando assim as suas especificidades, tanto para aquisição linguística, como para seu desenvolvimento cognitivo, motor, as formas de comunicação que podem desenvolver e, sobretudo, frente à realidade da atuação de profissionais especializados que atendam às necessidades do indivíduo surdocego.

Dessa forma, o conhecimento sobre o sujeito com surdocegueira e as singularidades de seu desenvolvimento, tornam-se elementos básicos para que a inserção social, de fato inclusiva, constitua-se de forma efetiva na realidade da educação e da sociabilidade.

Portanto, o interesse em contribuir para a produção de conhecimento nessa área específica da deficiência "surdocegueira", alia-se ao desejo de estabelecer relações que contribuam de forma interdisciplinar para o processo de desenvolvimento social, cognitivo, cultural, no atendimento educacional e na formação de indivíduos que atuem na sociedade, encontrando cada vez menos barreiras para sua constituição enquanto cidadãos.

Pensar a Educação, seja nos espaços escolares ou não escolares, como uma instância fundamental para o processo de desenvolvimento social dos indivíduos, demonstra a grande necessidade de (re)significar os sistemas e políticas socioeducacionais para que o atendimento aos indivíduos com deficiência se constitua de modo qualitativo. Por isso, a preocupação com as diferenças e especificidades da pessoa surdocega redobra a importância sobre o conhecimento dessa deficiência, a fim de que a acessibilidade dos sujeitos, independente de suas condições físicas e sensoriais, se efetive em seu contato com o mundo.

Essas afirmações se fundamentam a partir da Lei de Diretrizes e Bases da Educação Nacional - LDB (Lei no 9394/96), que estabeleceu, entre outros princípios: a "igualdade de condições para o acesso e permanência na escola", e recomendou que a 
educação para "educando com necessidades especiais" ocorra, preferencialmente, na rede regular de ensino. E para além das questões normativas, observa-se na sociedade o processo evolutivo frente à inclusão social e a diminuição das situações de segregação, discriminação, vulnerabilidade e precariedade, levando a busca pelo conhecimento específico ao lidar com as diferenças.

Galvão (2010) lembra que, no Brasil, a grande barreira para o desenvolvimento da educação e para a inclusão social de surdocegos se dá pela falta de profissionais mediadores, com formação específica sobre a surdocegueira, capazes de contribuir de forma funcional, para o estabelecimento primeiro do surdocego com o ambiente e do desenvolvimento relacional, a partir de linguagens que estabeleçam uma prática comunicativa, colaborando assim para o desenvolvimento cognitivo e social do sujeito. Esses profissionais funcionarão, portanto, como agentes mediadores, capazes de utilizar técnicas e recursos específicos para o atendimento educacional do surdocego.

Assim, é nessa realidade do atendimento socioeducacional aos indivíduos surdocegos que surge a atuação do profissional guia-Intérprete (GI), como mediador para a acessibilidade destes indivíduos, não apenas no aspecto comunicacional, como também nos aspectos estruturais didático-metodológicos na educação da pessoa com surdocegueira. Portanto, levanta-se como questão norteadora deste trabalho, a importância da formação e da atuação desses profissionais guias-intérpretes nos espaços escolares e não escolares.

Por isso, o objetivo geral desta reflexão é analisar a atuação do profissional guiaintérprete no atendimento a pessoas com surdocegueira, bem como, identificar os procedimentos de intervenção utilizados pelos guias-intérpretes a partir de práticas comunicativas com surdocegos e caracterizar fatores e aspectos que interferem na atuação dos profissionais guias-intérpretes, enquanto mediadores para a socialização do surdocego.

Assim, ao tempo que esta pesquisa permite a compreensão sobre a problemática da atuação dos guias-intérpretes no contexto do atendimento à pessoa com surdocegueira, percebe-se a amplitude desse problema de pesquisa a partir das novas inquietações surgidas e dos novos objetos de estudos que daqui podem surgir para a produção de conhecimentos outros e, sobretudo, de novas práticas que permitam o rompimento de paradigmas e de mudanças na sociedade em que vivemos. 


\section{Contextualizando a surdocegueira}

A surdocegueira tem se apresentado como um tema ainda pouco explorado na literatura especializada brasileira, quando comparada aos outros tipos de deficiências. Durante muito tempo, a perda sensorial da visão e audição, concomitantemente, caracterizou-se a partir dos aspectos da múltipla deficiência e não a partir da compreensão de uma deficiência específica, com características e especificidades peculiares.

A história da surdocegueira no Brasil, no âmbito da produção de conhecimento, ainda é muito recente, datada de 1953, quando o país recebeu a mundialmente conhecida Helen Keller. Influenciada por esta tão importante representante dos surdocegos no mundo, a educadora brasileira Nice Tonhozi Saraiva, que já trabalhava na educação de cegos no Instituto de Cegos Padre Chico em São Paulo passou também a empenhar eforços e conhecimento na educação dos surdocegos, a partir de 1962, quando regressou dos EUA.

O IBGE (1991) divulgou o número de 87.000 Múltiplos Deficientes e, entre esses, encontram-se, teoricamente, os surdocegos, por serem pessoas que têm mais de uma deficiência. Muitos, porém, podem não ter sido considerados nessa estatística, pois a descrição de cegueira e surdez no Manual do Recenseador (IBGE, 1990) somente considera com deficiência as pessoas com perdas sensoriais totais. O Censo mais atualizado apresenta questões sobre dificuldades visuais e auditivas mais abrangentes que o Censo anterior, considerando agora as perdas parciais. Se os dados forem tratados de forma conjugada poderão dar uma ideia aproximada da população com surdocegueira, mas ainda não foram obtidos dados precisos que permitam um planejamento correto das ações para o atendimento.

Só a partir do ano de 2002 que a surdocegueira surgiu nas primeiras discussões em documentos oficiais do país, através da publicação da coleção "Estratégias e Orientações Pedagógicas para a Educação de Crianças com Necessidades Educacionais Especiais" (BRASIL/MEC, 2002), pelo Ministério da Educação e Cultura. Sob essa realidade, os pesquisadores brasileiros reconhecem que ainda há uma pequena oferta de serviços especializados ao atendimento do surdocego e, geograficamente, as regiões Sul e Sudeste são as que se destacam com iniciativas mais aprofundadas, em relação às outras regiões do país. 
A partir de então, começaram a se ampliar os olhares e as reflexões a respeito dessa deficiência, desde o entendimento conceitual aos esclarecimentos a respeito das especificidades dos indivíduos surdocegos, sobretudo quanto as suas necessidades específicas para um bom desenvolvimento cognitivo e social. Apesar de o termo “surdocego" ser uma junção de duas perdas, a surdez e a cegueira, essa deficiência é única e apresenta características bem peculiares, pois enquanto o surdo é visualespacial, o cego é auditivo temporal (CADER-NASCIMENTO; COSTA, 2007).

Ao tratar sobre um possível quantitativo que represente os surdocegos no Brasil, Cader-Nascimento e Costa (2007) argumentam que o número de indivíduos sujeitos a surdocegueira é ainda maior do que se compreende nos dados estatísticos, visto que não são apenas surdocegos aqueles que têm perda total da visão e audição, mas também aqueles que apresentam perdas parciais, ampliando esse contingente populacional não apenas no Brasil, mas também no mundo.

Percebe-se que uma pessoa com surdocegueira tende a aprender a usar os sentidos remanescentes ou os resíduos auditivos e visuais a fim de estabelecer um meio de comunicação. Como visto, não necessariamente deve ser diagnosticada a surdez profunda ou severa, muito menos a cegueira aguda ou profunda, mas sim, pode-se caraterizar a deficiência a partir de graves perdas da visão e da audição, levando o sujeito a desenvolver variadas possibilidades para comunicação, favorecendo seu desenvolvimento nas atividades do seu dia a dia, bem como lazer, educação, trabalho e vida social.

Para McInnes e Treffry (1988), a pessoa surdocega não é um surdo que não pode ver, nem um cego que não pode ouvir. É uma pessoa singular, única, com características próprias. Dessa forma, a surdocegueira se torna uma condição que apresenta outras necessidades, diferentes daquelas apresentadas pela cegueira e pela surdez isoladamente.

Para o Grupo Brasil (2003), associação que promove atendimento à pessoa surdocega no Brasil, a surdocegueira é uma deficiência singular, que apresenta perdas auditivas e visuais, concomitantemente, em diferentes graus, levando a pessoa surdocega a desenvolver várias formas de comunicação para interagir com as pessoas e o meio ambiente. A partir desses pareceres, aponta-se a necessidade de um atendimento especializado para o desenvolvimento do indivíduo com surdocegueira, de modo que ele 
tenha as condições necessárias para aprender a se comunicar com o meio e se desenvolver socialmente de modo autônomo e independente.

Outro aspecto importante para o desenvolvimento do surdocego está relacionado à funcionalidade desse sujeito, a partir da capacidade que cada um terá para utilizar efetivamente o seu potencial de desenvolvimento, definindo assim o grau acometido pela deficiência. Para essa classificação, são atribuídos graus de perda para os surdocegos, que identificam, principalmente, o desenvolvimento da comunicação:

a) Baixo nível: indivíduos surdocegos que tenham sua comunicação limitada à aspectos básicos;

b) Nível médio: indivíduos surdocegos capazes de generalizar estratégias para a resolução de alguns problemas da vida cotitidiana e de levar uma vida menos depentende;

c) Alto nível: indivíduos surdocegos que desenvolvam estratégias de resolução de problemas e interesses. São capazes de levar uma vida ativa e ter aprendizagem regular em relação às suas necessidades naturais.

A importância de compreender o surdocego a partir da sua funcionalidade resulta em perceber as potencialidades de cada indivíduo, contextualizá-lo em seu ambiente e reconhecer as melhores estratégias para proporcionar a cada um deles o seu desenvolvimento individual.

Outra classificação importante é quanto ao período que o indivíduo foi acometido pela surdocegueira, principalmente no que se refere ao seu comprometimento linguístico. Assim, a surdocegueira pode ser classificada como congênita ou adquirida. Aqueles indivíduos que apresentam as perdas concomitantes de visão e audição antes de terem desenvolvido aquisição de língua, são classificados como surdocegos congênitos. Esses, sem dúvida, precisam de mais atenção para que possam desenvolver formas alternativas da comunicação.

O surdocego adquirido é aquele que apresenta uma deficiência sensorial, auditiva ou visual após adquirir uma língua, que pode ser a língua portuguesa, a de 
sinais, ou qualquer outro idioma, sem ter apresentado nenhuma deficiência anteriormente.

Estatísticas demonstram que o grupo mais numeroso de surdocegos no Brasil está representado por pessoas com 65 anos de idade ou mais, que apresentaram a deficiência tardiamente, principalmente após a aquisição de uma língua. Assim, pode-se afirmar que as causas da surdocegueira variam entre as fases: pré-natal, perinatal e pósnatal. Essas características se tornam essenciais para o desenvolvimento de um atendimento direcionado às necessidades do surdocego, uma vez que cada indivíduo apresentará um ritmo de desenvolvimento diferenciado e com potencialidades para estabelecer relação com o meio em que vive sob aspectos muito próprios.

Todos os indivíduos têm direito à comunicação, ao lazer, educação e interação social. No caso do indivíduo surdocego, a comunicação é a chave para que todos os outros direitos possam ser de fato efetivados. As crianças surdocegas congêntias precisam de muito mais cuidado, atenção e paciência no seu processo de aprendizado de uma linguagem. É importante, porém, que cada uma tenha suas habilidades, limites e personalidade respeitadas no processo de aquisição linguística.

\section{O guia-intérprete na mediação com o surdocego}

Compreender o universo das formas de comunicação que podem ser desenvolvidas pela pessoa com surdocegueira é fundamental para que a atuação de profissionais, responsáveis pela mediação da comunicação em vários contextos sociais, seja exercida da melhor maneira e, sobretudo, para proporcionar ao surdocego as condições necessárias para o acesso às informações.

Ao pensar nos contextos escolares, a presença desse profissional, mediador da comunicação, propiciará ao surdocego as ferramentas necessárias para o seu desenvolvimento no processo de aprendizagem. Através das variadas formas de comunicação, os profissionais podem estabelecer suas metodologias, permitindo desta forma, a acessibilidade do surdocego nos espaços escolares, considerando as especificidades da deficiência e, principalmente, as especificidades de cada pessoa surdocega. 
É muito comum que os familiares das pessoas surdocegas apresentem dificuldades em estabelecer vínculos comunicacionais em função de conhecerem as formas específicas de comunicação que são particulares e diferentes para cada sujeito surdocego. A ausência dos estímulos visuais e auditivos, na relação da mãe e seu filho com a deficiência, implicará, consequentemente, grandes dificuldades ao tentar estabelecer relações de comunicação que seriam naturais para o desenvolvimento de toda e qualquer criança, com ou sem deficiência. Dessa forma, se as relações sociais forem frágeis, também serão frágeis as possibilidades de a criança surdocega interagir com o mundo, relacionar-se e se desenvolver.

No processo de mediação que se estabelece entres os sujeitos, a interação se apresenta como a base para o desenvolvimento da linguagem, da aprendizagem e da aquisição de uma língua que, muitas vezes, acaba por não se estabelecer no ambiente familiar, uma vez que os membros da familia do surdocego, geralmente, não encontram ou desenvolvem outras formas de comunicação que não sejam a língua oral.

Sobre este aspecto, Bakhtim (2006) explicita alguns conceitos da percepção do "eu" e do "outro", bem como sobre o corpo interior e o corpo exterior. Para a criança com surdocegueira, a construção do seu "eu" pode se estabeler na medida em que suas sensações orgânicas, necessidades e desejos, em seu corpo interior, sejam constituidas a partir do "outro", em sua interação, a partir do que esse "outro" transmite e a partir do que a criança surdocega é capaz de compreender.

Esse amor da mãe e das outras pessoas, que desde a infância forma o homem de fora ao longo de toda a sua vida, dá consistência ao seu corpo interior. É verdade que não lhe proporciona uma imagem intuitivamente evidente do seu valor externo, mas lhe faculta um valor potencial desse corpo, valor que só pode ser realizado por outra pessoa (BAKHTIN, 2006, p. 47).

$\mathrm{O}$ autor compreende a interação a partir do olhar daquele que percebe a si mesmo e percebe o outro, observando que essa percepção de si se dá a partir daquilo que o outro apresenta na interação. O sujeito com surdocegueira, nessa compreensão, depende do outro e das experiências trazidas pelo outro, para que possa se estabelecer na construção de si mesmo. 
Nessa relação interativa, cabe ao outro oferecer as alternativas para o desenvolvimento do sujeito surdocego, a partir de elementos que contemplem a especificidade sensorial desse indivíduo. Por essas razões que se identifica o fundamental papel dos profissionais que atuam no atendimento ao surdocego, a fim de constituir um trabalho que proporcione ao indivíduo surdocego todas as possibilidades para seu desenvolvimento. Esses profissionais, com formação específica e, principalmente, conhecedores das singularidades da surdocegueira, serão os responsáveis pela mediação no processo de interação com o surdocego.

Inicialmente, esse papel de instrutor-mediador pode ser articulado pelo professor ou por outros indivíduos que sejam conhecedores dessa função (ALSOP; MAMER, 2002). Para o Grupo Brasil (2005 p.42), o instrutor-mediador é aquele que "faz a mediação entre a pessoa que é surdocega e o seu meio ambiente para capacitá-la a se comunicar com o mesmo e efetivamente receber informações não distorcidas do mundo a seu redor". Segundo Alsop e Mamer (2002), as atribuições de um instrutor-mediador no atendimento ao surdocego, são:

a) Facilitar o acesso à informação do ambiente pelo fato de as informações auditivas e visuais estarem indisponíveis ou restringidas;

b) Aumentar e tornar compreensível o acesso à informação;

c) Facilitar a comunicação receptiva e expressiva por todas as formas, antecipando eventos futuros;

d) Compreender o significado da comunicação expressiva, dos sinais e símbolos utilizados pela pessoa surdocega;

e) Promover o bem-estar social e emocional da pessoa surdocega;

f) Desenvolver e manter uma relação interativa baseada na confiança, estabelecendo um vínculo afetivo-emocional;

g) Entender o impacto da perda auditiva e visual na aprendizagem;

h) Facilitar o desenvolvimento de conceitos;

i) Promover a motivação para a participação nas atividades.

Os autores deixam claro que, apesar de as funções desses profissionais instrutores-mediadores serem muitas, eles antecedem a própria função de um professor, 
visto que as relações interpessoais acontecem diariamente em todos os ambientes nos quais o surdocego estiver inserido. Assim, quanto mais possibildiades de formas de comunicação forem apresentadas ao surdocego, maiores serão as suas condições de estabelecer experiências pessoais e coletivas. Por isso, o conhecimento do mediador deve ir além do simples processo de comunicação e passar por um estudo aprofundado dos aspectos linguísticos (signos, símbolos e significados).

A criança que apresentar surdocegueira congênita precisará receber uma mediação específica para que desenvolva linguagem, comunicação e fluidez em uma língua, já que a deficiência veio antes da aquisição desta. O grupo de surdocegos póslinguísticos, ou de surdocegueira adquirida em alguma fase da vida (depois da aquisição de uma língua), precisam do apoio da mediação para adaptar-se a sua nova condição de surdocego e para aprender um novo modelo de comunicação. Está, portanto, nas mãos do mediador, a ponte para que o surdocego seja capaz de sair de um mundo escuro e silencioso e desenvolver sua capacidade de autonomia e inclusão social.

\section{Formação e atuação do guia-intérprete: desenhando o método e a pesquisa}

Transitando por diferentes disciplinas e áreas de conhecimento das ciências humanas, como a Sociologia, a Antropologia, o Serviço social e a Educação, o método restaura os traços presentes em todo fazer teórico, acadêmico e normativo para o desenvolvimento do olhar de cada pesquisador.

Sob olhares e caminhos passíveis e possíveis de se percorrer, a presente pesquisa se propõe a uma abertura de enfrentamentos e de questionamentos que, dirigidos por uma inquietação investigativa, pretendem responder e, ao mesmo tempo, suscitar novos questionamentos sobre a problemática norteadora, tecendo assim, um constructo de saberes e conhecimentos com o propósito de contribuir para o conhecimento teórico, mas, sobretudo, para o fazer prático no qual a temática abordada se insere.

Para construir esse caminho metodológico, a escolha do estudo de caso, de caráter descritivo, favorece a aproximação entre o pesquisador e o campo de investigação. Este método se configura pela necessidade de investigar um fenômeno contemporâneo dentro do contexto real. Para o desenvolvimento da pesquisa foram selecionados participantes com algumas das seguintes características: 
a) Que atuassem em instituiçõoes de ensino na rede pública ou particular da cidade de Salvador, Bahia. b) Que atuassem em associações ou demais instituições de atendimento a pessoas surdocegas na cidade de Salvador. c) Que tivessem passado por cursos de formação de guias-intérpretes oferecidos por instituições especializadas. Foram selecionados onze guias-intérpretes, levando em consideração a aceitação de cada indivíduo, a fim de contribuir de maneira representativa frente ao grupo de profissionais que atuavam com surdocegos.

Necessário se faz esclarecer que, não tivemos como foco de discussão analisar os locais onde cada um dos guia-intérpretes atua na cidade de Salvador, visto que são profissionais autônomos e nem todos possuem vínculo empregatício nas instituições ou nas situações eventuais de atuação como guia-intérpretes. Dessa forma, a pluralidade dos ambientes onde os sujeitos pesquisados atuam, não reflete, nesta pesquisa, o objetivo principal para análise de suas atuações enquanto profissionais.

A elaboração da entrevista apresenta, em primeira instância, elementos exploratório-descritivos que identificam o perfil dos profissionais guias-intérpretes. Também foram considerados os elementos investigativos que contemplam a formação específica de cada profissional para atuarem no campo da guia-interpretação. A análise dos dados foi estabelecida de forma interpretativa, a fim de se compreender o fenômeno estudado, assumindo, em concordância com Myers e Wildemuth (1993) que a realidade é subjetiva e socialmente construída.

Por fim, o caminho metodológico traçado, e aqui apresentado, compreende o desenvolvimento de olhares e percursos do pesquisador, no intuito de conhecer a realidade da inclusão da pessoa com surdocegueira, com o direcionamento desse olhar sobre a atuação do profissional guia-intérprete, analisando, sobretudo, essa atuação e reconhecendo a necessidade da formação profissional para que o atendimento educacional ao surdocego se configure a partir de práticas inclusivas efetivamente de qualidade.

\subsection{Caracterização dos sujeitos da pesquisa}

Participaram da pesquisa, onze profissionais, sendo quatro do sexo masculino e sete do sexo feminino. A faixa etária estabelecida apresenta indivíduos com idade 
variando entre 28 e 39 anos. Como critério de inclusão/exclusão, foram contatados apenas sujeitos que haviam desenvolvido ou que ainda desenvolvem atendimento a pessoas surdocegas ou que passaram por curso de formação específica na área da guiainterpretação. O Quadro seguinte apresenta o desenho desse perfil biossocial e profissional dos sujeitos. Para atender ao critério estabelecido pela pesquisa, usaremos o modelo de identificação alfanumérico GI-1, GI-2, GI-3, para identificar cada um dos onze guias-intérpretes participantes.

\section{Perfil biossocial e profissional dos sujeitos da pesquisa:}

\begin{tabular}{|l|c|c|c|c|c|}
\hline SUJEITO & Idade & Nível de formação & $\begin{array}{c}\text { Formação } \\
\text { superior }\end{array}$ & Local de atuação & $\begin{array}{c}\text { Tempo de } \\
\text { atuação (anos) }\end{array}$ \\
\hline GI-1 & 28 & Superior & Letras/Libras & Eventos/ igrejas & 4 \\
\hline GI-2 & 31 & Superior & Letras/Libras & Eventos/ igrejas & 4 \\
\hline GI-3 & 32 & Superior & $\begin{array}{l}\text { Letras/Libras; } \\
\text { História. }\end{array}$ & $\begin{array}{c}\text { Eventos / } \\
\text { escolas }\end{array}$ & 10 \\
\hline GI-4 & 32 & Superior & Letras/Libras & Igrejas & Igrejas \\
\hline GI-5 & 35 & Superior & $\begin{array}{c}\text { Letras/Libras; } \\
\text { Pedagogia. }\end{array}$ & Menos de 1 \\
\hline GI-6 & 36 & Superior (em curso) & Pedagogia & Eventos & 6 \\
\hline GI-7 & 36 & Superior & Pedagogia & Escolas & 9 \\
\hline GI-8 & 37 & Médio & ------- & Escolas / igrejas & 5 \\
\hline GI-9 & 38 & Superior (em curso) & Letras/Libras & Escolas & Menos de 1 \\
\hline GI-10 & 38 & Superior & Letras & Igrejas & 5 \\
\hline GI-11 & 39 & Superior & Letras/Libras & Eventos & 1 \\
\hline
\end{tabular}

Fonte: entrevista com os sujeitos da pesquisa.

Essa característica biossocial dos entrevistados, ainda que não determine diretamente o caráter de qualificação para atuação no campo da guia-interpretação e do atendimento à pessoa surdocega, é representada pela faixa etária dos sujeitos, como um reflexo dos novos olhares para educação de pessoas com deficiências, e principalmente, sobre o próprio conhecimento a respeito da surdocegueira enquanto deficiência.

No quesito "escolaridade", não foram estabelecidos critérios de inclusão/exclusão, a fim de contemplar um maior número de participantes da amostra e poder analisar a importância da formação destes indivíduos para sua atuação profissional. Como resultado, foram observados os seguintes dados, no quadro 
apresentado: oito possuem pelo menos um curso de graduação, dois estão cursando formação em nível superior e um tem apenas o ensino médio concluído.

Importante observar que todos os guias-intérpretes de nível superior, apresentam essa formação no campo da educação, seja em pedagogia ou em Letras com habilitação em Libras. Esse fator é imprescindível para que seja analisado o nível de conhecimento específico no campo da educação especial e inclusiva, uma vez que, principalmente o curso de licenciatura ou bacharelado em Letras/Libras habilita o egresso para atuação e atendimento aos indivíduos surdos, e também surdocegos, que sejam usuários da Língua Brasileira de Sinais como principal recurso para comunicação. Assim, compreende-se que a maioria dos entrevistados tem uma formação inicial direcionada ao público com deficiência auditiva ou surdocegueira.

Este perfil demonstra que a formação em nível superior em $72 \%$ dos entrevistados é um importante fator a ser considerado, uma vez que as especificidades de formação constituem a busca por uma atuação profissional com qualidade, principalmente por se tratar de uma atuação que requer conhecimentos teórico/práticos nos campos da educação, comunicação, linguagens, sociologia, antropologia e saúde, associados à multidisciplinaridade das áreas de conhecimento em que esses sujeitos atuam. Tal fator se torna bastante expressivo à observação, principalmente pelo número de sujeitos graduados no curso de Letras com habilitação em Libras e em Pedagogia, bem como o expressivo número percentual (62,5\% dos graduados) de pós-graduados em Libras e em Tradução e Interpretação em Libras.

Para Maia, no processo de inclusão da pessoa com surdocegueira é "necessário levar em consideração a importância do profissional guia-intérprete e ou do instrutormediador, pois será a conexão da pessoa com surdocegueira com o mundo que o rodeia" (2005, p.107). Ao considerar que o profissional guia-intérprete é aquele que serve de canal de comunicação e visão entre a pessoa com surdocegueira e o meio no qual ela está interagindo, esse profissional deve apresentar algumas habilidades essenciais para que consiga transmitir todas as informações de modo fidedigno e compreensível à pessoa com surdocegueira. Seu trabalho basicamente consiste na transliteração ou interpretação, descrição visual e as funções de guia vidente (PETRONI, 2010). Por isso, tanto a formação inicial como a continuada se tornam imprescindíveis para a competência na atuação desse profissional. 


\subsection{Formação específica para atuação na área de guia-interpretação}

Para atender ao eixo proposto sobre a formação e atuação profissional dos guiasintérpretes, os profissionais foram questionados sobre seus cursos de formação tanto quanto ao item "capacitação na área de surdocegueira", quanto ao item "capacitação na área de guia-interpretação", oferecidos por alguma instituição credenciada, tenha sido ela a AHIMSA, GRUPO BRASIL, ABRASC, ou qualquer outra.

Essas informações, além de definir o perfil dos sujeitos desta pesquisa, estabelecem de forma clara o universo de profissionais que estão em condições de atuar como guias-intérpretes, confrontarão as dados exploratórios com os objetivos estabelecidos por esta proposta de pesquisa.

Dos onze guias-intérpretes pesquisados, cinco (45\%) possuem curso de capacitação na área de surdocegueira e seis (55\%) não têm nenhum curso de capacitação oferecido por instituições credenciadas. Aqueles com formação relatam que tiveram cursos realizados pelo Grupo Brasil, AHIMSA e pelo Instituto de Cegos da Bahia. Entre os que não realizaram cursos credenciados, dois afirmam ter participado de minicurso e oficina sobre surdocegueira, com carga horária de 4 horas, em congressos realizados na Bahia.

Em relação à formação na área de guia-interpretação, seis (55\%) dos entrevistados afirmam ter realizado curso de formação ministrado pelo Grupo Brasil, Instituto de Cegos da Bahia, ABRASC e AHIMSA. Cinco (45\%) dos entrevistados disseram não ter passado por nenhum curso de formação na área de guia-interpretação.

A partir do curso de formação de guias-intérpretes, as pessoas que já atuavam como tal, foram tomando consciência de seu papel e buscaram a formação para melhor capacitarem-se. A busca de formação e identidade do guia-intérprete acontece, de modo geral, isoladamente. À medida que esse profissional começa a participar de eventos, congressos e da luta pela fundação das associações, inicia-se um fortalecimento profissional, um convívio maior com os intérpretes de Língua de sinais e uma parceria com a associação.

Quanto ao tempo de experiência no atendimento à pessoa surdocega, cada um dos entrevistados apresenta um período, diferente. Nove deles já atuam como intérpretes de Língua Brasileira de Sinais com pessoas surdas e, durante esse período, realizaram 
sua formação complementar na área da guia-interpretação e surdocegueira ou, empiricamente, passaram por experiências profissionais nesse atendimento, como já apresentado na seção anterior.

As experiências profissionais vivenciadas pelos entrevistados estão inseridas no tempo de experiência enquanto tradutores/intérpretes da Língua Brasileira de Sinais, uma vez que, dos onze entrevistados, oito já exerciam atendimento com pessoas surdas antes de atuarem ou buscarem capacitação para o atendimento ao surdocego. Apenas dois declaram ter menos de um ano de atuação no atendimento a pessoas surdocegas, e oito possuem entre quatro a dez anos de experiência, o que denotaria, hipoteticamente, um grau de maturação importante para que a atuação profissional acontecesse. Contudo, a pesquisa demonstra que o tempo de experiência, necessariamente, não reflete a maturação correspondente ao tempo de atuação, quando considerado o número de cursos de capacitação ou de formação na área da surdocegueira e da guia-interpretação, principalmente por não encontrarem núcleos de apoio, associações específicas para surdocegos e instituições especializadas para o atendimento à surdocegueira na cidade de Salvador, na Bahia.

Considerando que a escola é um ambiente que potencializa o desenvolvimento cognitivo, social e cultural dos indivíduos, uma vez que as relações estabelecidas entre os educandos e seu contexto propiciam a sua construção individual e coletiva, argumenta-se que o espaço escolar para o desenvolvimento humano da pessoa surdocega deve ser tratado como ambiente fundamental de acesso e, consequentemente, permanência desse público na escola. Defende-se aqui a real necessidade do guiaintérprete para que o surdocego tenha suas especificidades de comunicação atendidas e, sobretudo, as condições para desenvolver-se plenamente. Quanto a isso, Plazas (2009, p 34) esclarece que:

El guía-interprete además de ser um facilitador linguístico y cultural entre usuários de diferentes lenguas o sistemas comunicativos, ayuda a conectar a la persona com surdoceguera com su entorno, actuando como sus ojos e sus oidos. De esta manera él promueve la integración y participación independente de la persona sordociega em su entorno. ${ }^{1}$ 
Recorre-se a Souza (2007, p, 159) para argumentar que a ação do intérprete, e aqui se contextualiza também a ação do guia-intérprete, é antes de tudo a de um educador. Souza defende que a ordem como o processo tradutório se constitui, muitas vezes é reduzida tecnicamente e é quase impossível de ser realizada nesse contexto. A ação de interpretar vai além e se torna impossível permanecer neutro diante desse cenário de subjetividades da comunicação entre os indivíduos. Para amenizar os problemas, nesse contexto de tradução, o processo de formação profissional é essencial.

De acordo com a percepção dos entrevistados, a falta de estrutura dos espaços escolares e não escolares; a falta de instituições de atendimento especializado ao surdocego e de órgãos que possam, tanto regulamentar as ações específicas, quanto fiscalizar o atendimento são fatores que comprometem a acessibilidade das pessoas com surdocegueira na sociedade, fortalecendo assim a realidade excludente desses indivíduos.

\subsection{Discussão da pesquisa: a comunicação mediando a inclusão do surdocego}

A reflexão sobre os aspectos concernentes à comunicação torna-se essencial nesta contextualização do surdocego, uma vez que é por meio desse mecanismo que os seres humanos se desenvolvem social e cognitivamente, ao estabelecerem as formas de aprendizagem. A comunicação entre indivíduos é um processo interpessoal sobre o qual os vínculos são constituídos; essa relação é estabelecida de diferentes maneiras e, segundo as possibilidades comunicativas de cada um, podem acontecer por meio de movimentos do corpo, objetos do ambiente ou a partir do desenvolvimento de um código linguístico.

O uso de objetos reais é uma possibilidade que consiste em interpretar uma atividade, ação ou situação por meio de um objeto, que adquire um valor simbólico. De acordo com Habermas (1991), com o uso de objetos a criança pode compreender e expressar as intenções comunicativas. Em outras palavras, a comunicação é um ato intersubjetivo que acontece entre duas ou mais pessoas, onde há uma troca entre significados e sentidos. O que foi mencionado anteriormente permite estabelecer a via pela qual se concebe a comunicação e seu caráter flexível, em relação às possibilidades demonstradas por cada sujeito. A comunicação não só acontece no âmbito verbal, mas 
transcende o não verbal, como modalidade discursiva que tem um conteúdo expressivo e compreensivo, apto para ser incluso no fenômeno comunicativo humano.

Nas crianças surdocegas congênitas e com múltiplas deficiências, a comunicação é o aspecto mais importante para o seu adequado desenvolvimento e, por isto, deve-se focar toda a atenção na implementação do programa educacional e terapêutico, já que é o ponto de partida para chegar a qualquer aprendizagem. Não saber o que acontece fora do corpo pode gerar angústia, instabilidade emocional e temor. A conexão com o mundo é feita através do tato, "adquirindo uma relevância especial nas suas necessidades de comunicação, obtenção de conhecimentos e aprendizagem" (ALVAREZ, 1991, p.37). Esse sentido, depois da visão e da audição, é o que pode oferecer mais informação.

Na compreensão dos aspectos de comunicação ligados à surdocegueira, serão apresentadas neste espaço, algumas das variadas formas e técnicas comunicacionais utilizadas pelos surdocegos a fim de manterem contato com o meio.

Dorado (2004) e Miles (2008) elencam as diferentes formas de comunicação que podem ser empregadas no processo de educação e socialização dos surdocegos. Essas formas podem depender do contexto em que os surdocegos estão inseridos e, sobretudo, das oportunidades que lhes são proporcionadas no contexto familiar, educacional e social, durante o período anterior e posterior à deficiência.

Para aqueles surdocegos adquiridos que já possuem experiências linguísticas, seja pela língua oral ou pela língua de sinais, considerando a presença de resíduos sensoriais, a necessidade de desenvolver formas de comunicação ocorrerá a partir da sua realidade individual e de seu meio, do grau de funcionalidade da deficiência e dos estímulos cognitivos que irão proporcionar o seu desenvolvimento.

Dessa forma, tanto para a surdocegueira congênita quanto para a surdocegueira adquirida, o acesso à informação se processa de maneira conflituosa, seja em seu aspecto receptivo como no expressivo e, na maioria das vezes, a acessibilidade se torna o grande entrave do indivíduo nos espaços sociais de aprendizagem. 


\section{A caminho de conclusões}

A mediação estabelecida para o surdocego, pensando o seu desenvolvimento e sua interação com o meio, caracterizará a necessidade de formação de profissionais preparados para esse atendimento, levando em consideração as especificidades da deficiência. Para cada surdocego, o atendimento pode apresentar diferentes caracteristicas em relação às formas de atendimento a outro indivíduo com a mesma deficiência, considerando principalmente sua funcionalidade, aquisição ou não de uma língua, e as variadas formas interativas para o desenvolvimento da comunicação.

Nessa realidade, identifica-se a presença do profissional guia-intérprete, que além de exercer a função de mediador deve desenvolver as competências necessárias no processo de tradução e interpretação entre as línguas que estiverem sendo contempladas em uma determinada situação comunicacional. O guía-intérprete cumpre mais funções do que um instrutor mediador, influenciando de forma considerável na interação do surdocego com o seu meio. Esse profissional, além de ser um canal de comunicação entre o surdocego e o meio no qual ele está inserido, tem o papel fundamental de compreender a mensagem, extrair o conteúdo linguístico e contextualizar o sentido na língua utilizada pelo receptor, o surdocego.

É importante que o guia-intérprete descreva o que ocorre em torno da situação de comunicação e facilite o deslocamento e a mobilidade do surdocego. Sua intervenção não exime os surdocegos de tomarem decisões próprias e fazer julgamentos. Esse profissional deve estimular o entendimento do portador da surdocegueira e fazer com que esse também seja entendido. Outra característica esperada do profissional guiaintérprete é o conhecimento aprofundado das diversas formas de comunicação que podem ser adotadas na educação e socialização dos surdocegos, identificando com antecedência qual a verdadeira necessidade desse indivíduo e qual língua pode atender melhor às suas expectativas de compreensão do mundo fora da escuridão e do silêncio. O que torna essencial também que se tenha domínio das Técnicas de Interpretação e da função de Guia-Interpretação.

Assim, compreende-se que a atuação do guia-intérprete está inserida nos processos de mediação e interação do surdocego com o meio, permitindo-lhe o acesso à informação, locomoção e comunicação, desde que, nesse processo de interação, seja feito uso de um sistema linguístico para que a comunicação se estabeleça. Por isso, o 
guia-intérprete representa um elemento de mediação com o mundo, e deve passar pelo processo de formação e de prática, para que o objetivo da sua atuação seja alcançado de forma efetiva.

Dorado (2004) argumenta que, para atuar na área de guia-interpretação, além da formação e da adequada atitude profissional, seguindo as questões de ética, esse profissional guia-intérprete deve apresentar características pessoais como: capacidade de observação, flexibilidade, versatilidade, autocontrole, responsabilidade, criatividade, alto nível de tolerância ao tato, sensibilidade, espírito de colaboração, habilidades linguísticas, de conunicação, e seleção de informação.

O trabalho do guia-intérprete possibilita junto à pessoa surdocega interação, acesso ao lazer, trabalho, educação, conhecimento de objetos, pessoas, favorecendo suas tomadas de decisões de maneira autônoma e efetivando seu direito de cidadão pleno. Essa profissão foi recentemente reconhecida pela Lei federal $n^{\circ} 12.319$ de $1^{\circ}$ de setembro de 2010. Destarte, vale ressaltar que, para que o trabalho do guia-intérprete seja plenamente reconhecido e eficiente, é necessário que sua formação seja constituída com respeito, ética e valor profissional.

\begin{abstract}
To reflect on the person with deafblindness and, above all, the service directed to the deafblind in the social and educational context, constitutes an academic need both in the production of theoretical knowledge and the practical interventions. This issue sets the paths taken by this article in order to investigate the importance of the guide-interpreter professional practice in serving people with deafblindness, from the communicative practices with the deafblind and characterizing the factors and aspects that interfere with his or her professional activities as a mediator for the socialization of the deafblind. From the socio-interactionist theoretical contributions, this work bases its reflections upon the understanding that the relationship of the deafblind with the environment constitutes an essential factor for the development of these individuals. The bibliographical research enables analysis of the lack of information and expertise on disability as a determining factor in the emergence of structural, programmatic, attitudinal and architectural barriers, which affect both the quality of services to the deafblind and the social reality of this individual, thus providing an excluding and segregating reality.
\end{abstract}

Keywords: Guide-interpreter, Educational inclusion, Social inclusion, Mediation, Deafblindness.

\title{
Resumen
}

Reflexionar sobre la persona con sordoceguera y, específicamente, sobre el servicio para los sordociegos en el contexto socioeducativo, constituye una necesidad académica, tanto en la 
producción de conocimientos teóricos, como en las intervenciones prácticas. Ese problema constituyelos caminos transitados por este artículo, con el objetivo de investigar la importancia de la actuación profesional del Guía-intérprete en el servicio de atendimiento a las personas con sordoceguera, a partir de las prácticas comunicativas con sordo-ciegos, caracterizando los factores y aspectos que interfieren en su actuación profesional como mediadores para la socialización del sordociego. A partir de los aportes teóricos socio-interaccionistas, este trabajo basa sus reflexiones en la comprensión de que la relación del sujeto sordociego con el medio ambiente constituye un factor esencial para el desarrollo de esos individuos. La investigación de carácter bibliográfico permite un análisis relacionado a la falta de informaciones y conocimientos específicos sobre la discapacidad como un factor determinante para el surgimiento de barreras de orden estructural, programática, actitudinal, arquitectónica, que afectan tanto la calidad de los servicios para los sordo-ciegos, como la realidad social de esos individuos, constituyendo así una realidad excluyente y segregativa.

Palabras-clave: Guía-intérprete, Inclusión educativa, Inclusión social, Mediación, Sordoceguera.

\section{Referências}

ALSOP, L. MAMER, R. Understing Deafblindness. Dba HOPE, 2002.

ALVAREZ Reyes, D. Discurso de Apertura, in Atas de la IV Conferencia Europea sobre sordoceguera, Dbl (Deafblind International), ONCE, Madrid, España. 1991.

BAKHTIN, M. Marxismo e filosofia da linguagem: problemas fundamentais do método sociológico da linguagem. 12. ed. São Paulo: Hucitec, 2006.

BRASIL. LDB - Leis de Diretrizes e Bases. Lei no 9.394. 1996. Disponível em: https://www2.senado.leg.br/bdsf/bitstream/handle/id/70320/65.pdf. Acesso em 27 ago 2016.

BRASIL, Ministério de educação. Estratégias e Orientações Pedagógicas para a educação de Crianças com necessidades Educacionais Especiais. Secretaria de Educação Especial. Brasília: MEC-SEESP, 2002.

CADER-NASCIMENTO, F. A. A. A.; COSTA, M. P. R. Descobrindo a surdocegueira: educação e comunicação. São Carlos: Edufscar, 2007.

DORADO G M. Sistemas de comunicación de personas sordociegas. Madrid, ONCE, 2004.

GALVÃO N.C.S.S. A comunicação do aluno surdocego no cotidiano da escola inclusiva. Tese (Doutorado em Educação) - Faculdade de Educação, Universidade Federal da Bahia, Salvador, 2010.

GRUPO BRASIL de Apoio ao Surdocego e ao Deficiente Múltiplo Sensorial. Folheto Informativo sobre Surdocegueira. São Paulo, 2003.

GRUPO BRASIL de Apoio ao Surdocego e o Múltiplo Deficiente Sensorial/Canadian International Development Agency-CiDA, 2005. 
HABERMAS, Jürgen. Textos e Contextos. Trad. Sandra Lippert Vieira. Lisboa: InstitutoPiaget, 1991.

IBGE. Manual do Recenseador, Instituto Brasileiro de Geografia e Estatística. Rio de Janeiro, 1990.

Censo Demográfico Brasileiro de 1991. Instituto Brasileiro de Geografia e Estatística. Rio de Janeiro, 1991.

MAIA, S. R. A Educação do Surdocego: Diretrizes básicas para pessoas não especializadas. Dissertação (Mestrado em Distúrbio do Desenvolvimento) Universidade Presbiteriana Mackenzie, São Paulo, 2004.

MILES, B. Overview on Deafblindness. DBILINK. Monmouth, 2008.

McINNES, John M.; TREFFRY, Jacquelyn A. Deaf-blind infants and children. Toronto: U of TP, 1988.

MYERS, M. WILDEMUTH, B M. Post-positivist research: two examples of methodological pluralism. Library Quarterly, v. 63, n. 4, p. 450-468, Oct.1993.

PETRONI, K. Deaf-blind Interpreting: Building on What You Already Know. Cadernos de Tradução, Vol. 2, No. 26, 2010. Disponível em:

http://www.periodicos.ufsc.br/index.php/traducao/article/viewArticle/15716

Acesso em: 21 mai. 2017.

PLAZAS, M. M. R. "Papel del guia-interprete" In: VI Congresso Nacional de La situacion Del sordo em Colombia, I Ecuentro Latino Americano de Interpretes e Guiasinterpretes de Lengua de Senas. Bogota, 2009.

SOUZA, Margarida M. P. de. Voando com Gaivotas: um estudo das interações na educação de surdos. Dissertação (Mestrado em Educação Brasileira). Pró-Reitoria de Pesquisa e Pós-Graduação. Fortaleza: UFC, 2007.

\footnotetext{
Nota

${ }^{1} \mathrm{O}$ guia-intérprete, além de ser um facilitador linguístico e cultural entre os usuários de línguas diferentes ou sistemas comunicativos, ajuda a conectar a pessoa com surdocegueira com o que está em sua volta, atuando como seus olhos e seus ouvidos. Dessa maneira, ele promove a integração e participação independente da pessoa surdocega em seu universo [nossa tradução].
} 